\title{
The Deflection of the Magnetic Ring for the Magnetic System $\mathrm{Co}_{x} \mathrm{Cu}_{1-\mathrm{x}} \mathrm{Fe}_{2} \mathrm{O}_{4}$
}

\author{
${ }^{1}$ Saleh H. Abud, ${ }^{1}$ Ali Kitab Attia and ${ }^{2}$ Raheem Abed Jeber \\ ${ }^{1}$ Department of Physics, Faculty of Science, University of Kufa, Najaf, Iraq \\ ${ }^{2}$ Department of Physics, College of Education, University of Al-Qadisiyah, Qadisiyah, Iraq
}

\begin{abstract}
In this study, cobalt and copper ferrite compounds were prepared by co-precipitation method, the nanocompound $\left(\mathrm{Co}_{\mathrm{z}} \mathrm{Cu}_{1 \cdot \mathrm{x}} \mathrm{Fe}_{2} \mathrm{O}_{4}\right)$ was then prepared by mixing cobalt ferrite and copper ferrite with different ratios of cobalt. The structural, morphological and magnetic properties of the resulted nanoparticles were studied. The XRD measurements showed dominant and high peaks located at $35.54^{\circ}$ and $35.31^{\circ}$ belong to the (311) $\mathrm{CoFe}_{2} \mathrm{O}_{4}$ and (211) $\mathrm{CuFe}_{2} \mathrm{O}_{4}$ planes, respectively at the same time, a decrease in grain size was observed with an increase in the ratio of copper ferrite as well as a decrease in the expansion of the magnetic hysteresis ring by increasing copper ratio.
\end{abstract}

$\underline{\text { Key words: Cobalt ferrite, copper ferrite, vibrating sample magnetometer, compounds, measurements, dominant }}$

\section{INTRODUCTION}

Now a days, nanomaterial science and nanotechnology has become very popular among scientists, engineers and industrialists due to its various applications in diverse field. Many works have been done on both bulk and nanomagnetic spinel ferrite compounds (Kumar et al. 2010; Shankar and Thapa, 2013; Xavier et al. 2013). Cobalt Ferrite $\left(\mathrm{CoFe}_{2} \mathrm{O}_{4}\right)$ belongs to the spinel oxide family it exhibits face-centred cubic structure in which every unit cell containing 32 of $^{2-}, 8$ of $\mathrm{Co}^{2+}$ and $\mathrm{Fe}^{3+}$ ions. The lattice of oxygen ions are distributed with 64 tetrahedral, 32 octahedral and 24 cations. The $8 \mathrm{Co}^{2+}$ and $8 \mathrm{Fe}^{3+}$ cations occupy half of the octahedral sites while the other $8 \mathrm{Fe}^{3+}$ ions occupy 8 of the 64 tetrahedral sites, therefore $\mathrm{CoFe}_{2} \mathrm{O}_{4}$ is a good example for an inverse spinel structure (Smit and Wijn 1959; Giannakopoulou et al. 2002). $\mathrm{CoFe}_{2} \mathrm{O}_{4}$ has been studied by many research groups due to it's remarkable physical properties such as high cubic magnetocrystalline anisotropy, high coercively, moderate saturation magnetization, high mechanical and chemical stability and electrically insulating behavior. These properties make $\mathrm{CoFe}_{2} \mathrm{O}_{4}$ has unique properties make it suitable for technological applications such as magnetic recording devices, gas sensors, catalysis, ferrofluids and medical applications such as drug delivery, biosensor and contrast enhancers in magnetic resonance imaging (Hashim et al. 2012; Murugesan and Chandrasekaran, 2015). Cobalt ferrite is synthesized by several methods such as sol-gel (Melo et al. 2015), hydrothermal (Kooti et al. 2013), co-precipitation (Herrera et al. 2013), thermal decomposition (Khan et al. 2014) and micro emulsion
(Sharma and Ghose, 2014). Among these methods, the co-precipitation methods has many advantages such as homogeneity, small obtained particle size, high purity, low temperature preparation and simple process (Feng et al. 2013).

\section{MATERIALS AND METHODS}

Experimental procedure: High purity $\mathrm{CoCl}_{2} \cdot 6 \mathrm{H}_{2} \mathrm{O}$, $\mathrm{CuCl}_{2} 2 \mathrm{H}_{2} \mathrm{O}$ and $\mathrm{FeCl}_{3}$ powders where used to prepare $\mathrm{CoFe}_{2} \mathrm{O}_{4}$ and $\mathrm{CuFe}_{2} \mathrm{O}_{4}$ by using co-precipitation method. An amount of powders was dissolved in $800 \mathrm{~mL}$ of distilled water with uniform heating of $60^{\circ} \mathrm{C}$ using magnetic heating stirrer. The $\mathrm{pH}$ of solutions was adjusted to be $8-9$ by using ammonia solution and $\mathrm{pH}-\mathrm{m}$, then the solution was filtered using Buchner filter and filter paper for $24 \mathrm{~h}$. After dehydration process, the dried mixture was combusted for $6 \mathrm{~h}$ and then grinded to get a loose powder. Finally, the powder sintered at $400^{\circ} \mathrm{C}$ for $6 \mathrm{~h}$ and subsequently grinded again to get very fine particles of $\mathrm{CoFe}_{2} \mathrm{O}_{4}$. Same steps were done to obtain $\mathrm{CuFe}_{2} \mathrm{O}_{4}$ (Table 1).

Nano composite of $\mathrm{Co}_{2} \mathrm{Cu}_{1-2} \cdot \mathrm{Fe}_{2} \mathrm{O}_{4}$ was prepared by mixing the above ferrites with different ratios of cobalt $(x=0,0.25,0.75,0.90$ and 1). After combusting the results, they pressed to $\left(5 \mathrm{ton} . / \mathrm{cm}^{2}\right)$ to get

\begin{tabular}{lcl}
\multicolumn{3}{l}{ Table 1: Preparation conditions of prepared samples } \\
\hline Sample & $\mathrm{x}$ & $\mathrm{Co}_{\mathrm{x}} \mathrm{Cu}_{1-x} \mathrm{Fe}_{2} \mathrm{O}_{4}$ \\
\hline $\mathrm{S}_{1}$ & 0 & $\mathrm{CuFe}_{2} \mathrm{O}_{4}$ \\
$\mathrm{~S}_{2}$ & 0.25 & $\mathrm{Co}_{0.25} \mathrm{Cu}_{0.75} \mathrm{Fe}_{2} \mathrm{O}_{4}$ \\
$\mathrm{~S}_{3}$ & 0.75 & $\mathrm{Co}_{0.75} \mathrm{Cu}_{0.25} \mathrm{Fe}_{2} \mathrm{O}_{4}$ \\
$\mathrm{~S}_{4}$ & 0.90 & $\mathrm{Co}_{0.90} \mathrm{Cu}_{0.10} \mathrm{Fe}_{2} \mathrm{O}_{4}$ \\
$\mathrm{~S}_{5}$ & 1 & $\mathrm{CoFe}_{2} \mathrm{O}_{4}$ \\
\hline
\end{tabular}

Corresponding Author: Saleh H. Abud, Department of Physics, Faculty of Science, University of Kufa, Najaf, Iraq 
disks while they pressed to $\left(3\right.$ ton. $/ \mathrm{cm}^{2}$ ) to get belts. The final sintering was at $800^{\circ} \mathrm{C}$. The crystallite structures of the prepared samples were studied by using Philips PW1710 X-ray diffractometer with a $\mathrm{Cu}-\mathrm{K}$ radiation source $\left({ }_{2}=1.5405 \AA\right)$. All prepared samples were denoted as in Table 1. Magnetic properties were studied by using Vibrating Sample Magnetometer (VSM).

\section{RESULTS AND DISCUSSION}

The structural characterizations and phase formation for cobalt and copper ferrites were carried out using X-ray diffraction at room temperature. Figure $1 \mathrm{a}$ and $\mathrm{c}$ shows the XRD patterns of $\mathrm{CoFe}_{2} \mathrm{O}_{4}$ and $\mathrm{CuFe}_{2} \mathrm{O}_{4}$ after initial combustion, respectively in which there are sharp peaks located at 20 equal to $35.64^{\circ}$ and $35.59^{\circ}$ correspond to the (311) $\mathrm{CoFe}_{2} \mathrm{O}_{4}$ and (211) $\mathrm{CuFe}_{2} \mathrm{O}_{4}$ planes, respectively in addition to other peaks of unidentified phases belong to impurities. After final combustion, Fig. $1 \mathrm{~b}$ and d, one can observe a dominant and high peaks located at $35.54^{\circ}$ and $35.31^{\circ}$ belong to the (311) $\mathrm{CoFe}_{2} \mathrm{O}_{4}$ and (211) $\mathrm{CuFe}_{2} \mathrm{O}_{4}$ planes, respectively. This findings are in agreement with

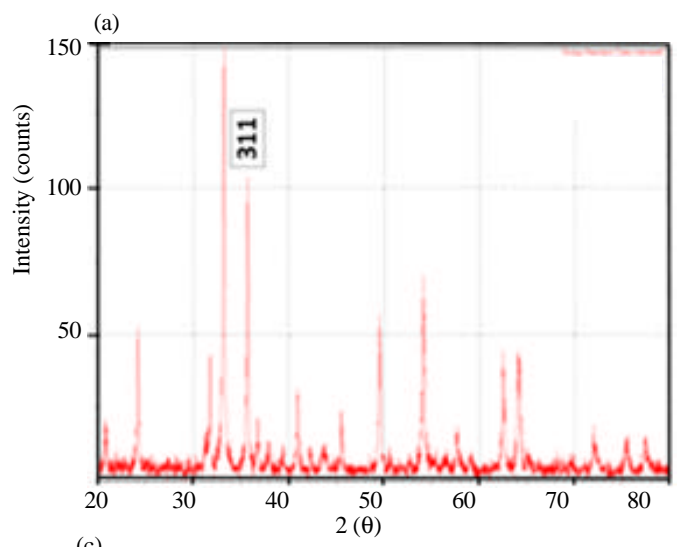

(c)

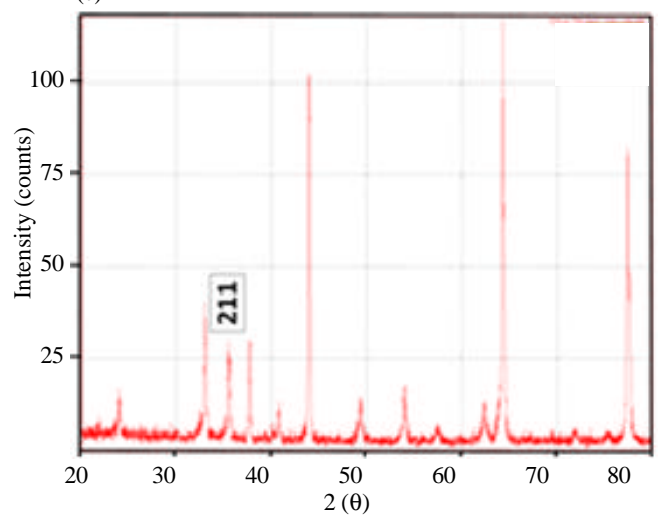

(JCPDS-77-0426) for $\mathrm{CoFe}_{2} \mathrm{O}_{4}$ and (JCPDS-34-0425) for $\mathrm{CuFe}_{2} \mathrm{O}_{4}$. The sharpness of peaks indicated the high crystalline nature of the expected cubic spinel structure, therefore, our conditions are required to prepare the spinel structure of cobalt and copper ferrites precipitates. The mean crystallite size D of the cobalt and copper ferrites was calculated using Debye-Scherrer formula (Abud et al. 2013) for the strongest peak after final combustion as follows:

$$
\mathrm{D}=\frac{0.9 \lambda}{\mathrm{B} \cos \theta}
$$

Where:

$$
\begin{aligned}
\therefore & =\text { The wavelength of the X-ray } \\
\mathrm{B} & =\text { The FWHM (in radians) } \\
\quad & =\text { The diffraction angle }
\end{aligned}
$$

The values of $\mathrm{D}$ are listed in Table 2 in which the value of $\mathrm{D}$ for $\mathrm{CuFe}_{2} \mathrm{O}_{4}$ is greater than that one of $\mathrm{CoFe}_{2} \mathrm{O}_{4}$ that is due to the cation radius of cobalt is greater than cation radius of copper. The magnetic measurements of the ferrites samples were recorded at room temperature by using VSM. The magnetic deceleration can help to understand the magnetic behavior of the samples as well
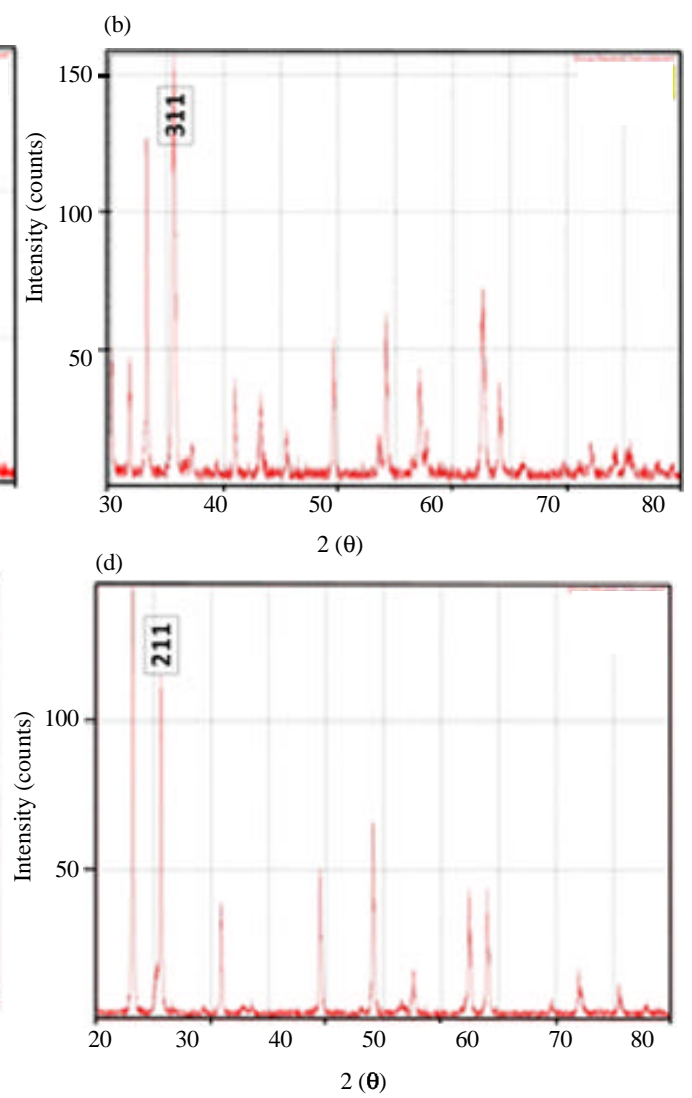

Fig. 1: XRD patterns of: a) $\mathrm{CoFe}_{2} \mathrm{O}_{4}$ after initial combustion; b) $\mathrm{CoFe}_{2} \mathrm{O}_{4}$ after final combustion; c) $\mathrm{CuFe}_{2} \mathrm{O}_{4}$ after initial combustion and d) $\mathrm{CuFe}_{2} \mathrm{O}_{4}$ after final combustion 

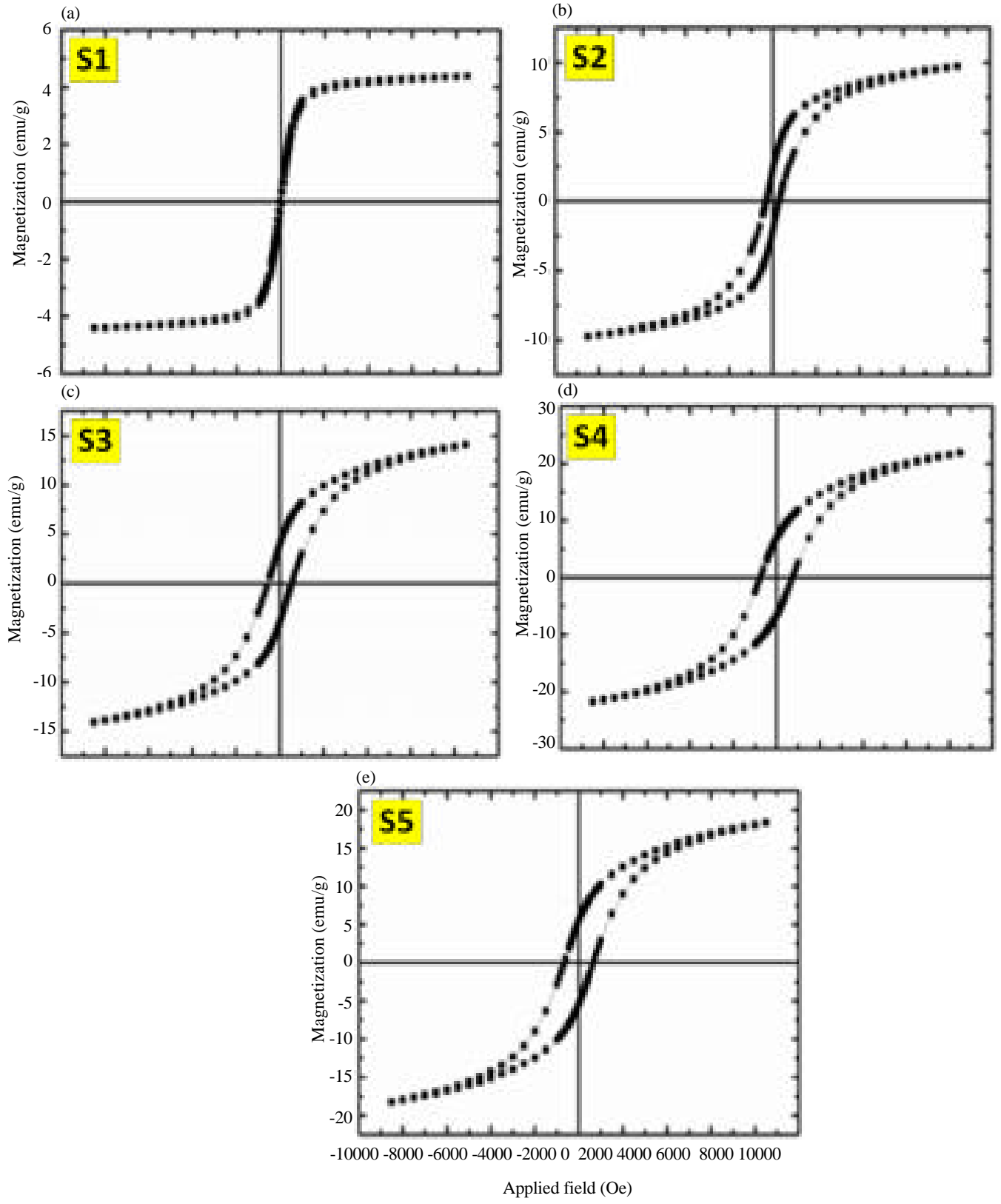

Fig. 2: a-c) Magnetic hysteresis curves of $\mathrm{Co}_{\mathrm{z}} \mathrm{Cu}_{1-\mathrm{z}} \mathrm{Fe}_{2} \mathrm{O}_{4}$ with different ratios of $\mathrm{Co}$ at sintering of $800^{\circ} \mathrm{C}$ for $6 \mathrm{~h}$

Table 2: The diffraction peak positions, FWHM and particles sizes of \begin{tabular}{lccc}
\multicolumn{4}{c}{ prepared samples after final composition for $6 \mathrm{~h}$ at $800^{\circ} \mathrm{C}$} \\
\hline Sample & $20^{\circ}$ & $\mathrm{FWHM}^{\circ}$ & $\mathrm{D}(\mathrm{nm})$ \\
$\mathrm{CoFe}_{2} \mathrm{O}_{4}$ & 35.5457 & 0.27830 & 31.3230 \\
$\mathrm{CuFe}_{2} \mathrm{O}_{4}$ & 35.5530 & 0.22470 & 38.7956 \\
\hline
\end{tabular}

as provide us the information about certain magnetic factors such as saturation magnetism, coercive force and remaining magnetism. Figure 2 shows the magnetization as a function of the strength of the applied magnetic field for all compounds. In which the narrow hysteric rings indicate that these materials are soft-ferrites; This result was confirmed by XRD data. At the same time, Magnetic saturation (Ms), remaining Magnetism $(\mathrm{Mr})$, coercive force $(\mathrm{Hc})$ and the ratio of $\mathrm{Mr} / \mathrm{Ms}$ were calculated and summarized in Table 3. It is observed that all above coefficients were increased with increasing the ratio of cobalt; this increasing is due to the difference in the crystallization and size of nanoparticles as well as to the distribution of positive ions in the four and eight-surface locations. A gradual decrease in saturation and alkaline magnification is noticed with increasing cobalt ratio in the compound 

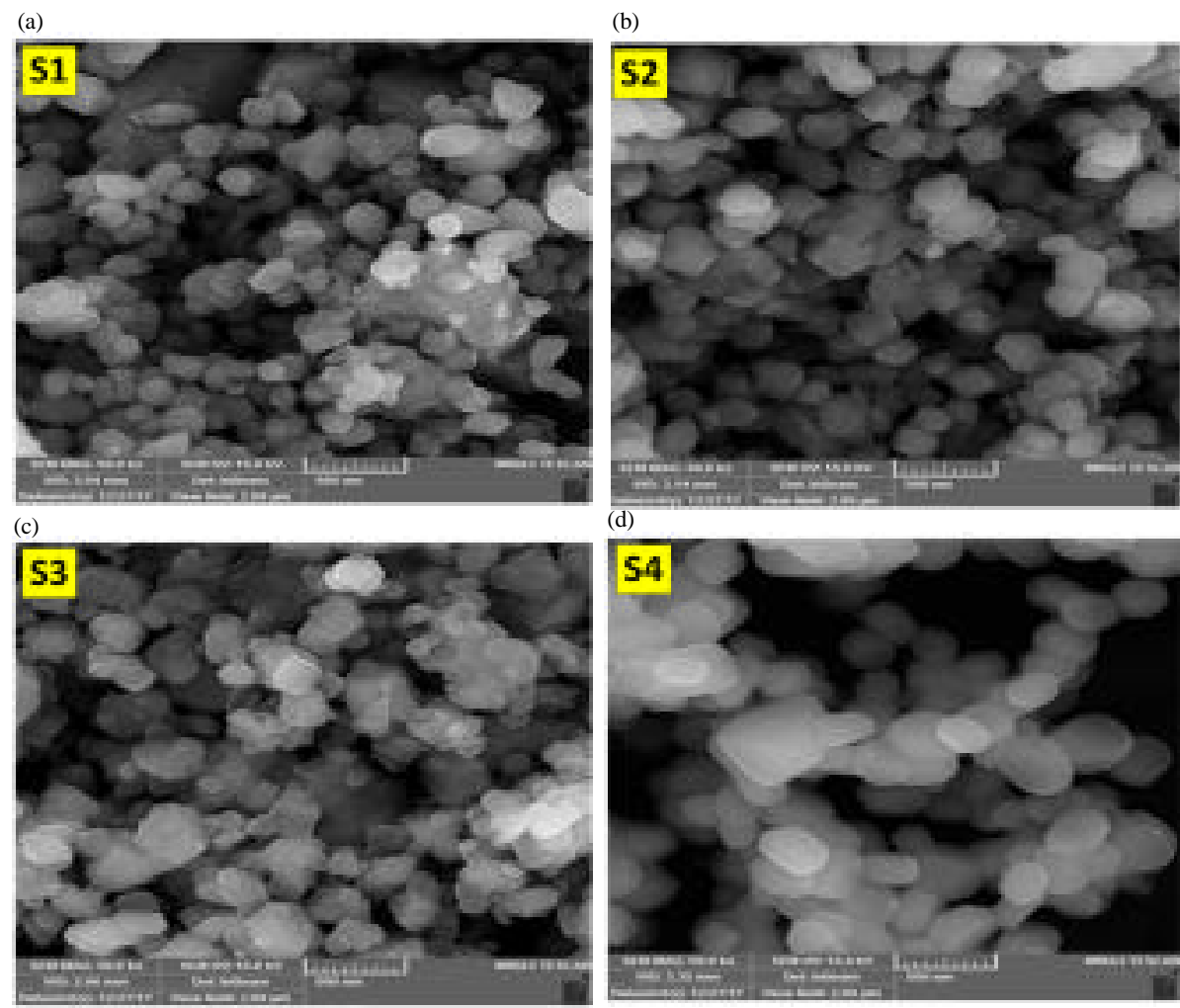

(d)
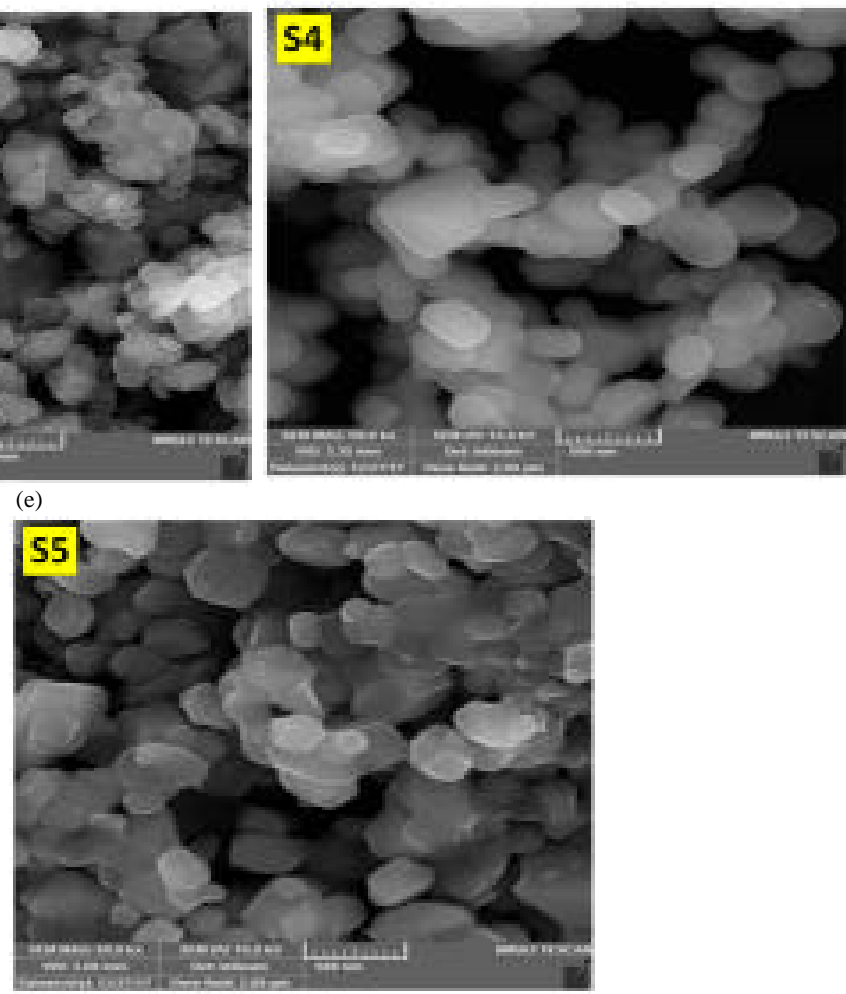

Fig. 3: a-e) FESEM images of $\mathrm{CoxCu}_{1}-\mathrm{xFe}_{2} \mathrm{O}_{4}$ with different ratios of Co

Table 3: Magnetic saturation (Ms), remaining Magnetism (Mr) and coercive force $(\mathrm{Hc})$ as a function of cobalt ratio

\begin{tabular}{lccrr}
\hline Sample & $\mathrm{Ms}$ & $\mathrm{Mr}$ & $\mathrm{Hc}$ & $\mathrm{Mr} / \mathrm{Ms}$ \\
\hline $\mathrm{S}_{1}$ & 4.388 & 0.363 & 87 & 0.083 \\
$\mathrm{~S}_{2}$ & 9.726 & 2.225 & 293 & 0.229 \\
$\mathrm{~S}_{3}$ & 14.06 & 3.978 & 520 & 0.283 \\
$\mathrm{~S}_{4}$ & 18.33 & 5.531 & 657 & 0.302 \\
$\mathrm{~S}_{5}$ & 21.87 & 6.883 & 731 & 0.315 \\
\hline
\end{tabular}

$\mathrm{Co}_{\mathrm{x}} \mathrm{Cu}_{1-\mathrm{x}} \mathrm{Fe}_{2} \mathrm{O}_{4}$ due to the rearrangement of cations tetrahedral and octahedral where cobalt and iron occupy more locations in four-surface locations. Because of the magnetic behavior of copper is lower than cobalt. It is clear that th coercive force decreased with decreasing the copper ratio in $\mathrm{Co}_{\mathrm{x}} \mathrm{Cu}_{1 \cdot \mathrm{x}} \mathrm{Fe}_{2} \mathrm{O}_{4}$; this can be attribute to the decrease in the anisotropic field which in turn reduces the energy of the area wall. FESEM images were used to investigate the surface morphology of the cobalt doped ferrite $\left(\mathrm{Co}_{\mathrm{z}} \mathrm{Cu}_{1-\mathrm{z}} \mathrm{Fe}_{2} \mathrm{O}_{4}\right)$ with different ratio $(0,25,0.75,0.90$ and 1) as shown in Fig. 3. The agglomeration process formed large clusters of particles. All samples exhibit nanoparticles with size increased with increasing cobalt ratio. The average diameter of particles for all samples is $97.82 \mathrm{~nm}$ as shown in Fig. 3 .The increasing in the particle size ascribe to the formation of $\mathrm{Cu}-\mathrm{O}-\mathrm{Fe}$ bonds on the surface which is turn retards the growth of crystal grains and assists to the separate particles. 


\section{CONCLUSION}

In summary, cobalt and copper ferrite compounds were prepared by co-precipitation method. The structural and magnetic properties of the resulted nanoparticles were studied. The XRD measurements showed dominant and high peaks located at $35.54^{\circ}$ and $35.31^{\circ}$ belong to the (311) $\mathrm{CoFe}_{2} \mathrm{O}_{4}$ and (211) $\mathrm{CuFe}_{2} \mathrm{O}_{4}$ planes. These results confirm that the ferrites have good crystalline quality with cubic spinel structure. The magnetic characteristics of $\mathrm{Co}_{\mathrm{x}} \mathrm{Cu}_{1-\mathrm{x}} \mathrm{Fe}_{2} \mathrm{O}_{4}$ with different ratios of cobalt were investigated. The magnetic saturation, remaining magnetism and coercive force were increased with increasing the ratio of cobalt.

\section{ACKNOWLEDGEMENT}

The researchers gratefully acknowledge support from University of Kufa.

\section{REFERENCES}

Abud, S.H., A. Ramiy, A.S. Hussein, Z. Hassan and F.K. Yam, 2013. A comparative study of the structural and electrical properties of n-type InGaN epilayer grown by $\mathrm{MBE}$ and commercially. Superlattices Microstruct., 60: 224-230.

Feng, J., L. Su, Y. Ma, C. Ren and Q. Guo et al., 2013. $\mathrm{CuFe}_{2} \mathrm{O}_{4}$ magnetic nanoparticles: $\mathrm{A}$ simple and efficient catalyst for the reduction of nitrophenol. Chem. Eng. J., 221: 16-24.

Giannakopoulou, T., L. Kompotiatis, A. Kontogeorgakos and G. Kordas, 2002. Microwave behavior of ferrites prepared via sol-gel method. J. Magnetism Magn. Mater., 246: 360-365.

Hashim, M., Alimuddina, S. Kumar, B.H. Koo and S.E. Shirsath et al., 2012. Structural, electrical and magnetic properties of Co-Cu ferrite nanoparticles. J. Alloys Compd., 518: 11-18.

Herrera, A.P., L. Polo-Corrales, E. Chavez, J. CabarcasBolivar and O.N. Uwakweh et al., 2013. Influence of aging time of oleate precursor on the magnetic relaxation of cobalt ferrite nanoparticles synthesized by the thermal decomposition method. J. Mag. Mater., 328: 41-52.
Khan, M.A., M. Sabir, A. Mahmood, M. Asghar and K. Mahmood et al., 2014. High frequency dielectric response and magnetic studies of $\mathrm{Zn}_{1 .}{ }_{\mathrm{x}} \mathrm{Tb}_{\mathrm{z}} \mathrm{Fe}_{2} \mathrm{O}_{4}$ nanocrystalline ferrites synthesized via microemulsion technique. J. Magnetism Magnetic Mater., 360: 188-192.

Kooti, M., S. Saiahi and H. Motamedi, 2013. Fabrication of silver-coated cobalt ferrite nanocomposite and the study of its antibacterial activity. J. Mag. Mater., 333: 138-143.

Kumar, P., S.K. Sharma, M. Knobel and M. Singh, 2010. Effect of $\mathrm{La}^{3+}$ doping on the electric, dielectric and magnetic properties of cobalt ferrite processed by co-precipitation technique. J. Alloys Compd., 508: 115-118.

Melo, R.S., F.C. Silva, K.R.M. Moura, A.S. DeMenezes and F.S.M. Sinfrionio, 2015. Magnetic ferrites synthesised using the microwavehydrothermal method. J. Mag. Mater., 381: 109115 .

Murugesan, C. and G. Chandrasekaran, 2015. Impact of $\mathrm{Gd}^{3+}$ substitution on the structural, magnetic and electrical properties of cobalt ferrite nanoparticles. Res. Adv., 2015: 73714-73725.

Shankar, A. and R.K. Thapa, 2013. Electronic, magnetic and structural properties of the filled skutterudite $\mathrm{EuFe}_{4} \mathrm{P}_{12}$ : LSDA and LSDA+U calculation. Phys. B: Cond. Matter, 427: 31-36.

Sharma, R.K. and R. Ghose, 2014. Synthesis of nanocrystalline $\mathrm{CuO}-\mathrm{ZnO}$ mixed metal oxide powder by a homogeneous precipitation method. Ceram. Intl., 40: 10919-10926.

Smit, J. and H.P.J. Wijn, 1959. Ferrites. Philips Technical Library, Eindhoven, Netherlands, Pages: 387.

Xavier, S., S. Thankachan, B.P. Jacob and E.M. Mohammed, 2013. Effect of sintering temperature on the structural and magnetic properties of cobalt ferrite nanoparticles. Nanosystems Phys. Chem. Math., 4: 430-437. 